\title{
Career patterns of dental hygienists in Scotland
}

\author{
P. D. Callis, ${ }^{1}$ and B. G. Wohlgemuth, ${ }^{2}$
}

\begin{abstract}
Objective To study career patterns of dental hygienists in Scotland
\end{abstract}

Subjects and methods Questionnaires were sent to all the dental hygienists enrolled with the General Dental Council in 1998 who had addresses in Scotland and those who were alumni of Scottish Schools of Dental Hygiene within the past 10 years.

Results There was a $58.7 \%$ response (334 out of 569). A net loss of trained hygienists was not found. The results suggested that most would remain in employment for at least 30 years and about a third would retire early. Half were in full-time employment and $60 \%$ had been in continuous employment. Most of the remainder had personal reasons for ceasing work. $39 \%$ had refused employment because of the poor level of pay.

Conclusions The introduction of the 2-year course has reduced output from schools of dental hygiene and demand for hygienists is high. Little hard information exists to support manpower planning in this area. This study suggests that there is little wastage of trained dental hygienists in Scotland. More data is required concerning employment opportunities and potential unmet demand for this group of PCDs to establish the number of training places required.

$\mathrm{T}$ he establishment of the Scottish Parliament and its responsibility for healthcare in Scotland creates the need to establish reliable data for healthcare planning within Scotland. Reliable data for manpower planning of dental hygienists in Scotland do not exist. This study was conducted to develop robust information about career patterns of dental hygienists in Scotland. Previous studies have concentrated on patterns of employment, attitudes to work and team working, ${ }^{1-4}$ two previous studies have examined samples of the Roll of Dental Auxiliaries for the whole of the UK, ${ }^{1,4}$ the previous survey was published in 1982. The first civilian dental hygienists qualified in Scotland in the early 1960s, almost 40 years ago and so a complete career analysis can be attempted for Scottish hygienists.

The Dental Auxiliary Review Group Report for the General Dental Council in 1998 highlighted the current importance and possible future evolution of all professionals complementary to dentistry. The subsequent acceptance of many of its recommendations creates a new environment for healthcare planners in which reliable baseline data are crucial to allow long-term plans to be developed.

The aims of this study were:

- To acquire current data on the career patterns and intentions of dental hygienists in Scotland.

${ }^{1}$ Consultant in Restorative Dentistry, Edinburgh Dental Institute, Lauriston Building, Lauriston Place, Edinburgh EH3 9YW; ${ }^{2}$ Computing Officer, Edinburgh Postgraduate Dental Institute, Lauriston Building, Lauriston Place, Edinburgh EH3 9YW

Correspondence to: $P$ D Callis

REFEREED PAPER

Received 15.11.99; accepted 06.03.00

() British Dental Journal 2000; 189:32-34
- To establish if possible typical career patterns for dental hygienists over a working lifetime.

- To provide robust information for dental professional bodies and government officers to allow effective manpower planning for this group of the professionals complementary to dentistry in Scotland.

\section{Materials and methods}

A copy of the 1998 General Dental Council Roll of Dental Auxiliaries was searched for those with addresses in Scotland. The three Schools of Dental Hygiene in Scotland were also contacted to obtain addresses of all the graduating students over the past 10 years. These lists were combined and a final circulation list established.

A questionnaire was developed with the Centre for Postgraduate Dental Education in Edinburgh to examine the employment history of those contacted and any underlying patterns; the questionnaire was anonymous. The questionnaire was sent with an explanatory letter to all those on the circulation list. Those who did not return the questionnaire within 3 months were sent a second copy to complete with a covering letter.

The returned questionnaires were collated into an ACCESS database. To simplify analysis the results were categorised into four decades according to the date of birth of the responders. These decade groups (20-29, 30-39, 40-49 and 50-59 years of age) were considered broadly equivalent to the first, second, third and fourth decades of work following the completion of training, the purpose of this study being to analyse work patterns up to the age of retirement.

\section{Results}

Five hundred and sixty-nine questionnaires were sent out and, after one reminder, 334 were returned; this is a $58.7 \%$ rate of return. Twenty-seven (about 10\%) of the questionnaires returned were not complete or contained invalid responses. This provided an accurate sample of 307 (about 54\%) which formed the basis for analysis. Responders were between 22- and 58-years-old with an age distribution that peaks in the second decade post qualification (Fig. 1).

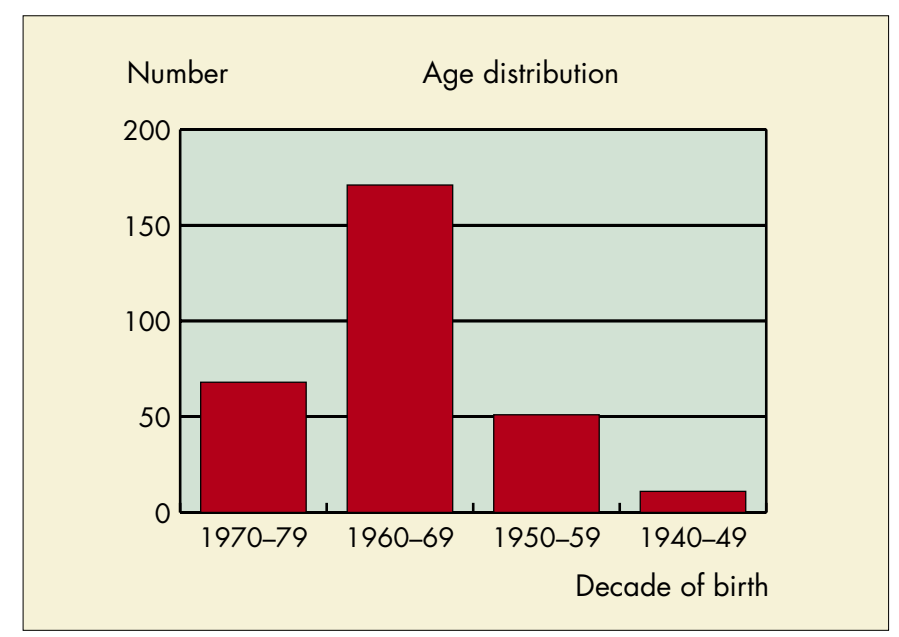

Figure 1 Age distribution of hygienists in Scotland 
When questioned about training and current residence a clear majority (73.8\%) of responders appears to stay in Scotland long term after training, with little apparent net loss from Scotland. The numbers of hygienists who move out of Scotland to work is more than balanced by those who now work there but who qualified elsewhere, mainly in England and Wales, with a small net flow into Scotland of about $2 \%$.

The majority $(69.4 \%)$ of responders worked in general dental practice with $17.5 \%$ working in the community dental services, 9.5\% in the hospital services and 9\% in the Dental Defence Agency.

Current employment was high with all age groups indicating only small numbers not currently in work (Fig 2). The oldest cohort (those in the last decade of work) indicated a tendency to retire early with only $63.7 \%$ in employment.

\section{$\%$ Employed at present -} age distribution

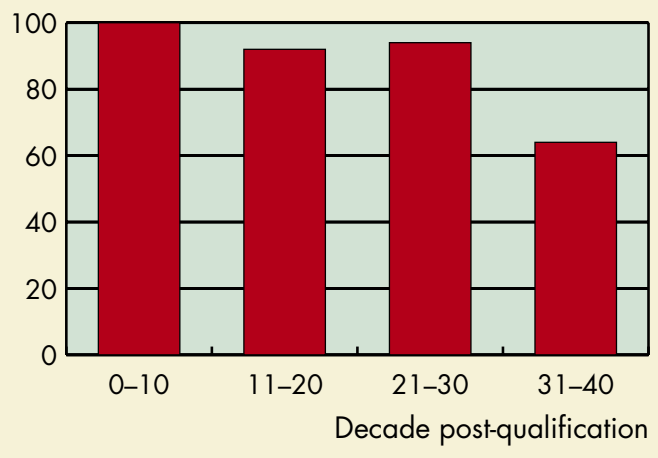

Figure 2 Employment levels of hygienists in Scotland

The majority of those in employment were working in one part time or whole time job with $10 \%$ or less in more than one part-time post. The proportion of those in full-time work reduced steadily with increasing age, falling until the final decade when the trend seemed to reverse (Fig. 3). The current period of employment varied from less than 1 year to 30 years with a mean of 7.4 years. Only $4 \%$ had remained in the same post for more than 20 years.

Questions concerning previous employment suggested that a clear majority of those in the first two decades of work had worked continuously up to that time, but by the third decade over twothirds had had interrupted employment. A clear majority of breaks in employment were for personal reasons. No clear pattern was seen in the questions concerning the continuity of the periods of employment beyond the clear indication that few hygienists had experienced more than three separate periods of employment.

Overall 39\% of responders had refused employment because of low pay, with almost $50 \%$ refusing posts in the hospital service. The small number (22) not currently in work showed a majority $(60 \%)$ who intended to work in the future with half of these intending to work within the next 2 years.

There was a high level of interest in retraining, especially as dental therapists or orthodontic auxiliaries (Fig. 4). Questions about future plans showed that most of those $(6.5 \%)$ who did not intend to work again as a hygienist were contemplating a career change. Interest in other careers was varied with no clear pattern, ranging from midwife to acupuncturist and countryside ranger. Less than $10 \%$ had any current plans to work outside the UK and only $2.6 \%$ had current plans to stop work completely.

\section{Discussion}

This study achieved a return rate of questionnaires of $58.7 \%$. The two similar surveys carried out in the UK achieved return rates of $39 \%{ }^{1}$ and $62 \% .{ }^{4}$ Higher response rates have only been achieved in smaller studies based on one school and contacting those who have graduated within the last 10 years. ${ }^{2,3}$ The achievement of a higher rate of response for this type of survey is therefore unlikely. This does unfortunately mean that extrapolation to the whole group including non-responders is difficult as a high proportion of non-responders may not be working as hygienists. This questionnaire was anonymous and so it was not possible to investigate this matter any further. A follow-up survey of a small random sample of those circulated with the questionnaire would help to clarify this situation.

The age distribution of the responders is shown in Figure 1 with a peak in the second decade. The age distribution in a similar study by Round and Sheiham ${ }^{1}$ was constrained by the time since hygienist training commenced (less than 20 years) and the study by Evans and Blinkhorn ${ }^{4}$ did not provide information on age distribution.

The peak in the second decade is hard to explain. The selected study population could be expected to result in a peak in the first decade, with the inclusion of the previous 10 years graduates from the three Schools in Scotland. The majority of the recent graduates would not be more than 30 -years-old and so this effect is likely to raise the numbers in the first decade not the second. The large numbers in the second decade could be caused by a much higher response rate from this age group. This aspect of the study merits further investigation.

The location of hygienists in practice was only investigated in one previous study ${ }^{4}$ and no analysis of movement post qualification was undertaken. The results of this study suggest that migration of qualified hygienists into and out of Scotland is in balance, with a possible small net flow northward.
Figure 3 Proportions of working Scottish hygientists in full or part-time employment.

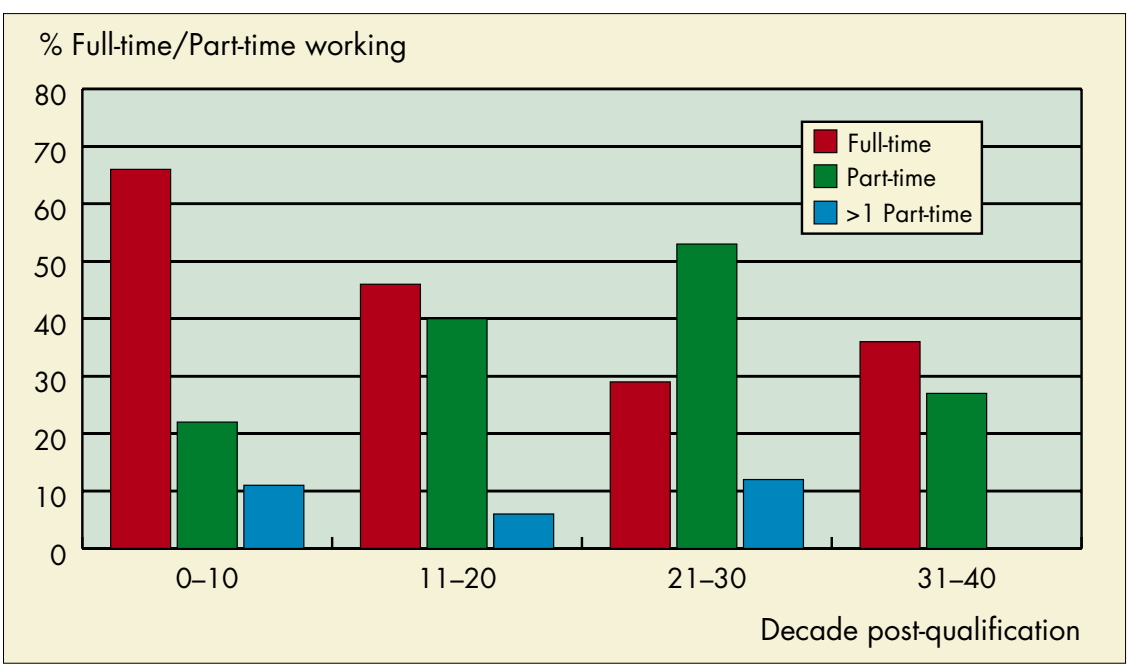




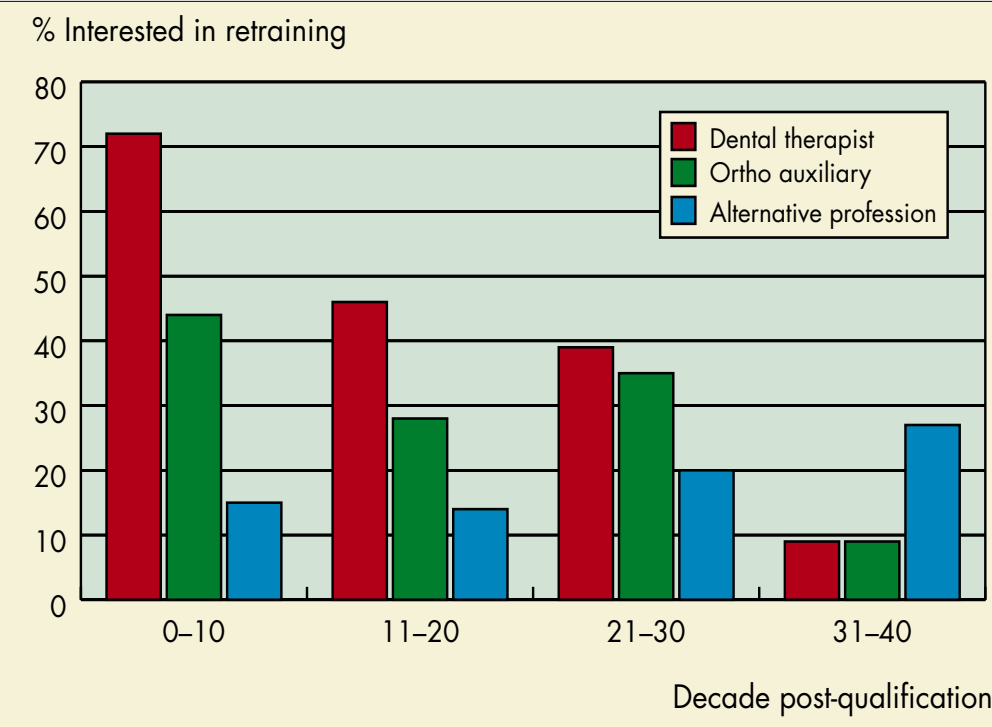

This study provides evidence to policy makers that training dental hygienists is good value for Scotland with little loss of trained hygienists. This study when put beside current data about numbers in work and numbers of vacancies will allow much improved manpower planning for this group of PCDs.

The examination of employment of responders in this study indicated rates of employment well above $90 \%$ for most of the first three decades of work, with perhaps a fall in the final decade. Round and Sheiham ${ }^{1}$ found a rate of $83 \%$, with Evans and Blinkhorn reporting a rate of $80 \% .{ }^{4}$ The reported rate of employment is considerably higher in the present study and may indicate an effect caused by the change in a 2-year training course and consequent reduction in output or may reveal a true increase in employment of hygienists.

Working patterns in the present study revealed a complex picture (Fig. 3), during the first three decades those in full-time work declined with age from $66 \%$ to $30 \%$ while those in a single parttime post rose from $22 \%$ to $53 \%$. The trend appears to reverse in the final decade. Only in the second and third decades do the results of this present study agree with Round and Sheiham ${ }^{1}$ who showed $50.5 \%$ in full-time work. However, their data showed only $5.4 \%$ in one part-time post which is much lower than the present study. This suggests a tendency for employment in multiple part-time posts to have reduced over the last 25 years.

In the present study numbers in more than one part-time post were small in all decades and never rose above $12 \%$. This is surprisingly small compared with $27.3 \%{ }^{1}$ and $28 \%{ }^{4}$ in earlier studies. It may be accounted for by a misinterpretation of the questionnaire in the present study, which may have prompted those working ten sessions per week in several part time posts to indicate only full-time employment.

About $70 \%$ of dental hygienists are employed in General Dental Practice in Scotland compared with $68 \%{ }^{1}$ and $60 \%{ }^{4}$ in previous studies. The results reported by Round and Sheiham ${ }^{1}$ provide the only data that allows further analysis of employment in other branches of dentistry and their results and those of the present study are very similar.

No other study has addressed the issue of the retirement of hygienists. This study seems to indicate a retirement age of between 50 and 60 although the numbers are small.

The length of continuous periods of employment varied enormously. In the present study, $4 \%$ reported working in the same job for more than 20 years with a mean of 7.4 years. One of the reasons for this turnover may be the effect of poor pay in some posts with $39 \%$ of those in all areas of dentistry having refused one or more posts because of poor pay. The level of dissatisfaction with the pay on offer was lowest in the Community Dental Services at $40 \%$, with $50 \%$ in the hospital services, $43 \%$ in the GDS and $66 \%$ in the DDA. This suggests that, apart from the Armed forces where the sample is small, the worst problem exists in the hospital services. It is certainly true that rates of pay tend to be poor in the hospital services for hygienists. This study suggests that the current levels of pay for dental hygienists in the hospital dental services are not sufficient to ensure successful recruitment, as is often found in practice.

Satisfaction with levels of current pay were examined by Evans and Blinkhorn ${ }^{4}$ who found only $9 \%$ dissatisfied with rates of current pay, a clear majority did not consider themselves to be poorly paid. The difference between the two studies probably explains the relatively slow turnover of hygienists. No other comparable study has addressed this area.

Retraining was of interest to a majority of those in the first decade. This interest declined with time with the exception of those thinking of an alternative profession where interest increased steadily with increasing age. Round and Sheiham ${ }^{1}$ also found a high level of interest (61\%) in further training.

The aim of the present study was to provide some reliable data for long-term planning of hygienist services. A follow-up survey is required to demonstrate whether the sample in this study is truly representative. To complete the overall picture more study is also required of current numbers of hygienists working in Scotland and the number of potential vacancies that exist. The effect of current pay levels on recruitment could be usefully examined, especially in the cash-limited services in the hospitals and the community dental services.

The results of this questionnaire suggest a typical Scottish hygienist will have trained in Scotland and will stay there to work for more than 30 years. They will be employed in a succession of full-time posts in general dental practice for the first 10-15 years when they are likely to take part-time posts. They have not refused employment because of poor pay but would be interested in retraining as a dental therapist.

\section{A Scottish Chief Scientist's Mini Project Grant No: K/OFR/15/9/F27 supported} this work.

1 Round A, Sheiham A. Report on Dental Hygienists 1973. Dent Health 1974; 13: $17-20$.

2 Hale H, Forwood F, Jarrell B B, Edwards G M. Career patterns of Northeast Louisiana University Dental Hygienists. J Louis Dent Ass 1978; 39-42.

3 Hillam D. Career patterns of dental hygienists qualifying from the Liverpool Dental Hospital School of Dental Hygiene. Br Dent J 1989; 310-311.

4 Evans C L, Blinkhorn A S. A national survey of dental hygienists. Br Dent J 1982; 153: 309-310. 